\title{
Trabalho escravo contemporâneo como um problema de saúde pública
}

\author{
Modern-day slavery as a public health issue
}

Luís Henrique da Costa Leão ${ }^{1}$

${ }^{1}$ Grupo de Estudos Ambientais e de Saúde do Trabalhador, Instituto de Saúde Coletiva, Universidade Federal de Mato Grosso. Av. Fernando Corrêa 2367, Boa Esperança. 78060-900 Cuiabá MT Brasil.

luis_leao@hotmail.com
Abstract Modern-day slave labor is one of the most pernicious and persistent social problems in Brazil. In the light of the need to implement a national occupational health policy, this paper discusses slave labor as a public health concern, highlighting possibilities for broadening strategies for vigilance and comprehensive care for this specific working population. Exploratory qualitative research was carried out based on the "social construction of reality" proposed by Lenoir, Berger and Luckmann. The investigation consisted of a theoretical review of modern-day slave labor on the national and international scene within the scope of the human, social and public health sciences and an analysis of social and political practices to tackle modern-day slave labor was conducted in the State of Rio de Janeiro. Semi-structured individual and group interviews with workers and representatives of social movements and public institutions were organized. The results reveal the theoretical and practical dimensions of slave labor and its relations with the health field and highlight the role and potential of public health in the enhancing of vigilance practices and health care of workers subjected to these chronic social conditions.

Key words Public health, Modern-day slave labor, Social construction, Occupational health
Resumo O trabalho escravo contemporâneo (TE) é uma das mais injustas e persistentes problemáticas sociais do Brasil. Frente à necessidade de implantação da política nacional de saúde do(a) trabalhador(a), este artigo discute o trabalho escravo como problema de saúde pública, destacando possibilidades de ampliar as estratégias de vigilância e atenção integral a essa população específica de trabalhadores. Foi realizada uma pesquisa qualitativa, exploratória, sob o referencial teórico da construção social da realidade, conforme Lenoir, Berger e Luckmann. O estudo consistiu em uma revisão teórica sobre TE no cenário nacional e internacional no âmbito das ciências humanas, sociais e de saúde pública e uma análise das práticas de enfrentamento ao TE na região norte do estado do Rio de Janeiro. Foram efetuadas entrevistas semiestruturadas, individuais e coletivas, com trabalhadores e representantes de movimentos sociais e instituições públicas. Os resultados demonstram dimensões teóricas e práticas sobre o TE e suas relações com o campo da saúde e destacam o papel e o potencial da saúde pública no fortalecimento das práticas de vigilância e atenção à saúde dos trabalhadores submetidos a essas condições sociais crônicas.

Palavras-chave Saúde Pública, Trabalho escravo contemporâneo, Construção social, Saúde do trabalhador 


\section{Introdução}

O Brasil é uma formação social e econômica complexa e comporta muitas contradições. É a sétima economia do mundo, líder no mercado internacional na produção do etanol da canade-açúcar ${ }^{1}$, ao passo que persistem em seu território a superexploração de trabalhadores vulneráveis em termos de educação e renda ${ }^{2}$. Nesse cenário, o trabalho escravo contemporâneo (TE) é uma de suas mais graves, injustas e persistentes problemáticas sociais.

Longe de ser um fenômeno recente, isolado e pontual, o TE compôs parte da história econômica brasileira e da América Latina, em diferentes modalidades, especialmente no setor canavieiro. "O rei açúcar e outros monarcas agrícolas" deixaram "veias abertas” na América Latina e Brasil, pois a produção de riquezas para a Europa era simétrica à exploração do trabalho escravo de negros e indígenas, degradação do solo e geração de misérias que repercutem até os dias atuais ${ }^{3}$.

Essa escravidão clássica fora abolida, mas no capitalismo contemporâneo emergem novas e distintas formas de TE bem frequentes em várias cadeias produtivas assumindo diferentes nomenclaturas, como trabalho análogo à escravidão, trabalho forçado, servidão por dívida e tráfico humano. Trata-se de um conjunto de fenômenos vinculados aos modelos de desenvolvimento econômico e ao padrão de acumulação capitalista. Envolvem situações onde o trabalhador tem um conjunto de direitos negligenciados, é exposto a condições de trabalho perigosas e tratado como propriedade ou levado a trabalhar sem consentimento ou por coerção $0^{4}$.

Estima-se que haja 35,8 milhões de pessoas submetidas a essas formas laborais e países como Mauritânia, Uzbequistão, Haiti, Paquistão, Índia estão entre os de maior prevalência ${ }^{4}$. No Brasil ele é encontrado nas cadeias produtivas de álcool e açúcar, carne, milho, soja, café, confecções, construção civil, etc. Em 2013, foram libertos 2.208 trabalhadores em área urbana e $1.228 \mathrm{em}$ área rural ${ }^{5}$. De 1995 a 2013 o Ministério do Trabalho e Emprego (MTE) realizou 1.572 fiscalizações e resgatou 46.478 trabalhadores gerando $\mathrm{R} \$$ 86.320 .330 de indenização ${ }^{6}$.

O campo da saúde pública vem ocupando lugar marginal, tanto na produção de conhecimento quanto nas estratégias de enfrentamento ao TE. Esse tema ainda não foi objeto de investigações específicas em saúde coletiva, de forma que, em buscas bibliográficas nas bases de dados Bireme e SciELO, nenhum artigo recuperado vincula-se a esse campo.
Em nível internacional, a relação entre saúde e TE contemporâneo aparece na literatura embora também não seja sistematicamente estudada. Publicações discutem riscos e efeitos corporais e psíquicos provocados por essa condição. Dentre elas estão a exposição a riscos de doenças e violências na jornada da região de origem ao território da produção; transporte, comida e hidratação inadequados, além de ambientes de trabalho e moradia perigosos, precários e insalubres ${ }^{7}$. São reportados sentimentos de isolamento, vergonha, traição e transtornos mentais e comportamentais como estresse pós-traumático, consumo excessivo de álcool e drogas, lesões físicas e traumatismos decorrentes de acidentes ${ }^{7}$.

Quanto às estratégias brasileiras de intervenção no TE, o setor saúde é cotado na composição de comissões nacionais e estaduais responsáveis pelas ações e considerado parceiro fundamental nos Planos Nacionais de Erradicação do Trabalho Escravo. Os referenciais teóricos, estruturas, recursos humanos e materiais do setor saúde, entretanto, ainda estão subutilizados nesse conjunto de práticas ${ }^{8}$.

Frente a essa lacuna e à necessidade de implantação da política nacional de saúde do trabalhador e da trabalhadora (PNSTT) ${ }^{9}$, este artigo discute o TE como um problema de saúde pública, destacando possibilidades de ampliação das estratégias de vigilância e atenção integral a essa população específica de trabalhadores.

\section{Trajetória metodológica}

Foi realizada uma pesquisa exploratória de base qualitativa com dois focos: uma revisão teórica sobre TE no cenário nacional e internacional no âmbito das ciências humanas e sociais e da saúde pública; e uma parte empírica que abordou as práticas de enfrentamento ao TE na região norte do estado do Rio de Janeiro.

Foram reunidas publicações de organismos internacionais, manuais, cartilhas, artigos e livros científicos, bem como documentos públicos institucionais e legislações do setor saúde do Brasil. Esse material foi identificado em bases de dados científicas e institucionais, sites de organizações como a OIT, de movimentos sociais e ONGs nacionais e internacionais. Essas referências foram lidas integralmente e analisadas a fim de delimitar aspectos teóricos e conceituais do TE e também de identificar interseções do setor saúde com a problemática do TE.

No sentido de trazer outros elementos histórico-conceituais cruciais para a compreensão 
desse fenômeno, foram analisadas ainda obras clássicas de Hegel, Marx e autores contemporâneos, como Kevin Bales e José de Souza Martins, considerados centrais para a discussão do TE.

A pesquisa de campo visou compreender a construção social do problema do TE no norte fluminense e as práticas de erradicação existentes por parte de instituições públicas (incluindo o setor saúde) e movimentos sociais. Essa região foi escolhida por ter sido a última a banir a escravidão clássica no Brasil e porque nos últimos anos acumulou mais de sete mil casos de TE contemporâneo. Desde 2003 denúncias e lutas de trabalhadores, grupos sociais e instituições ocorreram de modo mais contundente, a ponto de, em 2009, ter sido considerada campeã nacional de TE.

Cinco entrevistas semiestruturadas (uma coletiva e quatro individuais), compostas por questões abertas sobre (a) características do TE na região, (b) práticas de combate existentes e (c) envolvimento da saúde pública frente à questão foram realizadas com trabalhadores e representantes de movimentos sociais, instituições públicas e membros do Comitê Popular de Erradicação do Trabalho Escravo do Norte Fluminense (CPETE). Foram entrevistados individualmente dois membros do CPETE e dois representantes de serviços públicos da região. Tais entrevistas ocorreram nos locais de trabalho de cada um desses sujeitos, em ambiente reservado. A entrevista coletiva foi realizada com cinco trabalhadores, dos quais dois haviam sido escravizados e os outros três militam contra o TE. Esses sujeitos foram indicados pelo MST regional e a entrevista ocorreu em um de seus assentamentos.

Toda a investigação ocorreu entre 2007 e 2013, sendo a coleta de dados empírica entre 2011 e 2012. Foram observados os aspectos éticos da pesquisa em saúde conforme a Resolução 196/96, vigente à época, e todos os entrevistados assinaram o termo de consentimento livre e esclarecido autorizando a pesquisa e a publicação dos dados.

As entrevistas foram gravadas e transcritas e as análises foram referenciadas em teóricos da sociologia do conhecimento, especificamente, Berger e Luckmann ${ }^{10}$ e Lenoir ${ }^{11}$, no que tange à construção social da realidade. Sob esse referencial discutem-se os problemas de saúde pública enquanto uma construção social e, em seguida, apresentam-se dimensões teóricas e práticas sobre o TE e suas relações com o campo da saúde. Por fim, com base na pesquisa empírica, destacase o papel da saúde pública no fortalecimento e ampliação das práticas de vigilância e atenção à saúde dos trabalhadores.

\section{A construção social \\ dos problemas de saúde pública}

Proteger, promover, vigiar e restaurar a saúde da população compõem o leque de ações em saúde pública. Programas, recursos, estratégias dos serviços, instituições e profissionais responsáveis são organizados para intervir em problemas considerados prioritários. Geralmente, ganham notoriedade certas endemias, epidemias e agravos específicos, como AIDS, dengue, hanseníase e outros. Um problema de saúde pública é definido pelo potencial epidêmico do fenômeno, a carga de impactos no indivíduo e na sociedade, sua natureza, severidade, extensão, gravidade e possibilidade de controle ${ }^{12}$. Para que um fenômeno seja reconhecido como problema de saúde pública ocorre todo um processo social complexo envolvendo atores, instituições e especialistas. Isso, porque os “problemas" não são fenômenos naturais, imutáveis e idênticos, independentes da região e dos contextos social, cultural, econômico e político em que emergem.

Existe um processo social tanto de produção de saúde-doença quanto de definição das situações que deveriam ou não ser consideradas alvos da intervenção em saúde pública. Assim, aquilo que em dado momento é considerado problema resulta de construções processuais, históricas e culturais determinadas em função de saberes e poderes em jogo e mediante o conjunto de atores e instituições interessadas.

As sociologias médicas e do diagnóstico contribuem para a compreensão desses processos, e, desde 1970, vêm analisando diferentes práticas de construção social das doenças e a influência dos mercados e corporações de saúde ${ }^{13}$. Os sistemas de classificação de doenças, sofrimentos e sintomas e as práticas de cura são convenções sociais conformados historicamente. Consequentemente, várias doenças e manifestações de sofrimento, a exemplo daquelas de difícil diagnóstico decorrentes de exposição química a poluentes ambientais ou agravos à saúde dos trabalhadores, não são "naturalmente" reconhecidas pelos saberes biomédicos hegemônicos. Apenas depois de longos processos sociais, eles emergem na cena pública, por meio de agentes interessados em trazer à tona categorias específicas para exigir soluções políticas e institucionais ${ }^{13}$.

Berger e Luckmann ${ }^{10}$ e Lenoir ${ }^{11}$ demonstram o quanto os problemas sociais são instituídos pelos instrumentos que forjam a realidade social. Existe uma ampla variação dos mesmos em função do contexto, épocas e regiões. Assim, para um determinado fenômeno ser considerado 
um problema social existem agentes sociais em operação, estratégias em prática, relações e representações dominantes em torno de seu reconhecimento e legitimação. $\mathrm{O}$ que deve ser explicado é justamente o fato de uma realidade ser tomada em dado momento como um problema social ${ }^{11}$, uma vez que todo problema de saúde pública pressupõe um trabalho de reconhecimento e legitimação.

Nesse processo, ocorrências graves e geradoras de sofrimentos entram na pauta das políticas e práticas de saúde enquanto outras são deslegitimadas. Isso fica claro no que tange às situações de saúde-trabalho.

A categoria trabalho enquanto fator determinante do processo saúde-doença foi institucionalizada no campo da saúde coletiva por forças sociais dos movimentos de trabalhadores, profissionais dos serviços públicos e acadêmicos na década de 1980. Questões relativas aos trabalhadores eram consideradas problemas da Previdência Social, Justiça do Trabalho e Ministério do Trabalho e Emprego (MTE). Entretanto, casos crescentes de benzenismo, câncer de pleura decorrente da exposição ao amianto, Lesões por Esforços Repetitivos entre outras doenças ocupacionais, no fim de 1980, exigiram um insistente trabalho social, político e legal para elevar essas situações à esfera de ações do Estado, com novos enfoques no setor saúde, principalmente porque as áreas hegemônicas não respondiam às necessidades da classe trabalhadora.

O reconhecimento de eventos relativos à saúde dos trabalhadores como problemas de saúde pública tem sido um processo social, político e institucional longo e contínuo que ainda perdura, apesar dos avanços em sua institucionalização no SUS.

Da década de 1980 a 2000 muitas tentativas de institucionalização se seguiram e até mesmo a criação da Rede Nacional de Atenção Integral à Saúde do Trabalhador (Renast), em 2002, foi uma estratégia para implementar práticas nos serviços de saúde que considerem o trabalho como mediador do processo saúde-doença.

Atualmente o desafio está na implementação da PNSTT, requerida em 1986 pela sociedade civil e publicada somente em 2012. Ou seja, apesar da existência de riscos e vulnerabilidades e da gravidade de acidentes de trabalho, doenças ocupacionais e sofrimentos dos trabalhadores, seu reconhecimento social como problema de saúde pública não é algo natural. No cotidiano dos serviços de saúde, eventos como esses são deslegitimados pelas controvérsias em torno dos nexos causais e até mesmo acidentes de trabalho, por vezes, não são considerados responsabilidade da saúde pública por profissionais e gestores das secretarias de saúde, hospitais e ambulatórios.

Existe um jogo de forças mediado pela cultura e condições históricas dos contextos e instituições de saúde que opera a favor ou contra o reconhecimento da relação trabalho-saúde como problema público do âmbito da saúde. É nesse jogo de (não)reconhecimento/(des)legitimação que se encontram as situações de TE contemporâneo no âmbito da saúde.

\section{Entendimentos sobre trabalho escravo contemporâneo}

A maneira de nomear e entender os fenômenos tipificados como TE pode facilitar ou criar barreiras para sua inserção no rol de problemas sanitários. Esse tema exige apurado rigor teórico e uma consciência social crítica ${ }^{14}$, pois geralmente cria espetáculos midiáticos e um imaginário desvinculado da realidade a ponto de banalizar a terminologia e levar qualquer condição a ser considerada TE - trabalhadores com salários baixos, mulheres donas de casa, arrocho nas relações de trabalho, etc. ${ }^{14}$

Essa temática tem raízes históricas e filosóficas importantes. No século XIX, tendo a expansão europeia e a escravização dos povos africanos, americanos e asiáticos como pano de fundo, a filosofia de Hegel utiliza a dialética do senhor -escravo como metáfora para explicar a consciência de $s^{15,16}$. Segundo o filósofo, em sua "Fenomenologia do Espírito", o escravo seria um "ser para o outro", ou seja, uma coisa entre o senhor e o objeto do seu desejo ${ }^{16}$.

Da dialética hegeliana emergiu o pensamento de Marx, pautado na análise das relações sociais de produção. O materialismo histórico-dialético demonstra a ruptura do sistema capitalista com o escravismo clássico enquanto modo de organização da sociedade. Uma das principais características do capitalismo e sinal da superação do escravismo seria a liberdade do trabalhador - liberdade de vender sua força de trabalho em troca de um salário ${ }^{17}$. Esse trabalhador livre é também livre dos meios de produção ${ }^{14}$, e assim a exploração nesse sistema ocorre a partir da extração de mais valia e alienação no processo de trabalho e não mais por meio de encarceramentos físicos. Afirmar a manutenção da escravidão no seio do capitalismo seria então um equívoco teórico.

Não é incomum, entretanto, perceber alusões a uma escravidão contemporânea por meio das 
servidões modernas. A ideia da submissão a sistemas de regras impostos por governos totalitários, por exemplo, redutor das liberdades individuais, foi desenvolvida na tese de Von Hayek em "O caminho para a servidão"18. A obra histórica de La Boetie em "Discurso sobre a servidão voluntária"19 contribui para compreensão da servidão voluntária do sujeito contemporâneo que vincula-se às formas de dominação modernas, adere ao consumo como estilo de vida e encontra um alento para o medo e desamparo do mundo globalizado na docilidade e submissão ao sistema.

As novas formas de escravidão eclodiram em função do crescimento populacional pós $2^{\mathrm{a}}$ guerra mundial e das transformações econômicas que aumentaram a riqueza e a concentração de terras nas elites empobrecendo a maioria da população ${ }^{20}$. Essa escravidão não seria mais caracterizada por compra-venda ao modo clássico de escravismo. Se no passado o ponto definidor da escravidão era a propriedade, atualmente é o controle da pessoa com fins de exploração econômica e o uso da violência ${ }^{20}$.

Essas formas coercitivas e violentas de exploração são temporárias e circunstanciais e o controle total de uma pessoa para obtenção de lucro não é mais baseado na cor da pele, mas em diferenças de classe econômica, religião e tribo ${ }^{14,20}$. Ou seja, houve uma passagem das legalidades da posse para as práticas de controle. A escravidão não desapareceu, mudou suas formas ${ }^{20}$. A questão central é que essas relações de trabalho são utilizadas como táticas de redução do custo da produção.

Além da dimensão econômica o TE também tem um componente cultural, pois é uma manifestação perene em certas culturas, como as da China e Sudão, até mesmo em países desenvolvidos e em regiões onde faltam condições de pleno exercício da liberdade ${ }^{14,20}$.

Elementos históricos, econômicos e culturais podem favorecer as manifestações atuais de TE, por isso é preciso reconhecer as especificidades do capitalismo nas diferentes regiões e a consequente diversidade histórica das formas de exploração. No Brasil, por exemplo, a lei Aurea tratou apenas da escravidão do negro e não de outras formas de escravidão, como a servidão por dívida corrente no Brasil já em 1877 nos seringais que exploravam trabalhadores famintos vindos do nordeste do país. Não por acaso, a escravidão por dívida ainda é muito presente no Brasil ${ }^{14}$.

O TE abrange também a negação de direitos trabalhistas e previdenciários, exposição a más condições de trabalho, alimentação e moradia, aprisionamentos por dívida, ameaças físicas e psíquicas. Envolve humilhação, vergonha de voltar para casa com menos recursos, remuneração insuficiente para a manutenção do trabalhador, falta de higiene, exposição a riscos ocupacionais e de contágio de doenças infectocontagiosas e até assassinatos $^{21}$. Trata-se de uma relação social caracterizada pela negação do outro em um regime de "desumanização" no qual pessoas são tratadas como "menos humanos".

Para a legislação brasileira esse tipo de trabalho se caracteriza por submeter o outro a trabalhos forçados ou jornada exaustiva, sujeição a condições degradantes de trabalho e restrição de sua locomoção em razão de dívida contraída com o empregador ${ }^{8}$.

O reconhecimento público da existência do TE contemporâneo no Brasil ocorreu em 1995 e, desde então, foram institucionalizadas várias ações de combate por meio de movimentos sociais e ONGs, da participação de brasileiros na Junta de Curadores do Fundo Voluntário da ONU contra as formas contemporâneas de escravidão, das iniciativas da OIT e das estratégias MTE e Ministério Público do Trabalho (MPT) ${ }^{21}$.

O Brasil atualmente já tem um quadro de legislações, ações e experiências bem sucedido ${ }^{8}$. O reconhecimento, a legitimação e a institucionalização das práticas de combate ao TE, não obstante, ocorreu predominantemente nos âmbitos policial, jurídico-penal, no MPT, na Justiça do trabalho e no MTE. Consequentemente, as principais práticas implementadas têm sido eminentemente repressoras, preventivas e educativas ${ }^{8}$. Apesar do uso constante da expressão "erradicação" do TE, a linguagem do campo da saúde, o envolvimento do SUS no planejamento, execução e avaliação das ações interventivas é ínfimo.

O TE, entretanto, é um fenômeno de múltiplas dimensões - sociais, econômicas, culturais e, consequentemente, sanitárias. Não se limita ao campo jurídico e legal sob a responsabilidade de instituições do judiciário e do MPT e MTE. Também não é somente crime e caso de Política, posto que fere o Código Penal Brasileiro e legislações trabalhistas e previdenciárias. É um problema complexo e multideterminado que demanda atuações intersetoriais e participativas também da responsabilidade do setor saúde.

\section{Saúde pública e trabalho escravo contemporâneo}

Iniciativas para atenção à saúde relacionada ao trabalho remontam aos cuidados médicos 
com os escravos, afinal, seu desgaste representava perdas financeiras para os donos. No V século A.C., Platão já verificava diferenças existentes entre os cuidados médicos dispensados a escravos e homens livres ${ }^{22}$, enquanto que no Brasil escravocrata existiam várias práticas médicas voltadas aos primeiros como especialidade da medicina veterinária.

Naqueles períodos os escravos eram sustentados pelos seus proprietários, e, atualmente, são tratados como descartáveis, sem coberturas de direitos sociais e trabalhistas ${ }^{20}$, de forma que ao se acidentarem ou sofrerem de uma doença ocupacional, são excluídos da produção e substituídos, sem garantias de assistência.

É importante frisar que o TE contemporâneo envolve pessoas mais pobres e vulneráveis ${ }^{14}$. A população alvo do TE no Brasil é predominantemente de homens jovens com média de 32 anos, cor preta/parda (80\%) com renda de 1 a 2 salários mínimos, mais provenientes das regiões nordeste, norte e centro-oeste ${ }^{23}$. A maioria é analfabeta funcional, com cerca de 3,8 anos de estudo e início de vida profissional anterior aos $16 \operatorname{anos}^{23}$. É uma parcela da sociedade submetida a padrões históricos de exclusão social e injustiças da formação social brasileira.

Essa população sofre os efeitos da violência, maus tratos, humilhações e insalubridade dos ambientes de trabalho, tem imagem de si bastante negativa e suas principais aspirações são elementos básicos: melhores moradias para a família, trabalho e formação ${ }^{23}$.

Daí a importância de maiores investimentos do setor saúde na compreensão e intervenção nas condições dessa população, porque as relações sociais de produção capitalistas geram determinantes e condicionantes de sua saúde que precisam ser mais conhecidos.

Certamente o SUS, especificamente no âmbito da saúde do trabalhador e saúde-ambiente reconhece o problema do TE, mas faltam estratégias direcionadas ao seu enfrentamento considerando os determinantes da saúde dessa população e seus efeitos.

O manual de gestão da Renast, por exemplo, reconhece que "As condições encontradas no trabalho rural, como, por exemplo, relações de trabalho à margem da legislação, ocorrência de mãode-obra escrava e, (...), faz com que a população que vive e/ou trabalha no campo encontre-se mais descoberta e vulnerável aos problemas de saúde relacionados ao trabalho" ${ }^{24}$. O problema não passa despercebido no Manual de doenças relacionadas ao trabalho do Ministério da Saúde: "Tradicional- mente, a atividade rural é caracterizada por relações de trabalho à margem das leis brasileiras, não raro com a utilização de mão-de-obra escrava” ${ }^{25}$. Na 13a CNS também foi apontada a necessidade de: "Estabelecer políticas (...) que previnam danos aos trabalhadores da área rural, que são submetidos a regimes de escravidão" ${ }^{26}$. E a PNSTT afirma expressamente o papel da vigilância no combate ao TE. Um dos objetivos da política é "fortalecer a Vigilância em Saúde do Trabalhador e a integração com os demais componentes da Vigilância em Saúde, o que pressupõe: (...) f) contribuição na identificação e erradicação de situações análogas ao trabalho escravo" .

Alguns mapeamentos apresentam-se como poderosos meios de caracterização desses problemas e seu enfrentamento. O mapa dos conflitos ambientais no Brasil, por exemplo, demonstra conflitos socioambientais que envolvem TE na exploração de povos indígenas no Amazonas, nos sistemas de precarização do trabalho de marisqueiros e pescadores artesanais no Ceará, no agronegócio da soja no Maranhão e Mato Grosso, na expulsão de trabalhadores de suas terras no Pará para a construção de estradas de ferro, na coação de agricultores em fazendas do Acre, na escravidão por dívida para a produção da indústria do fumo no Sul, na produção de cana em Pernambuco e Rio de Janeiro, entre outros ${ }^{27}$. A ocorrência de TE em vários processos de produção, portanto, é reconhecida pelo campo da saúde e mais passos precisam ser dados para compreender-intervir nessas situações.

\section{Saúde pública e trabalho escravo contemporâneo no norte fluminense}

No norte fluminense os casos de TE ocorrem essencialmente no setor canavieiro. Esse processo produtivo apresenta dois principais problemas: as queimadas da cana que fazem chover fuligem por toda a cidade de Campos e as situações de TE. Trata-se de um padrão de exploração marcado pelo uso predatório do ambiente e do ser humano, expressando tendências do modelo de desenvolvimento capitalista neoliberal que agudiza as desigualdades sociais, a precarização e os sofrimentos $^{28,29}$.

A investigação sobre as situações de trabalho nesse setor revelou elementos determinantes da saúde dos trabalhadores e seus efeitos, similares àqueles informados pela literatura nacional e internacional.

O TE na região se manifesta nas más condições, endividamento e cerceamento da liberdade 
entre migrantes, na "clandestinidade" dos trabalhadores locais (ausência de carteira de trabalho assinada e negação de direitos), nas relações de subserviência entre fazendeiros e seus "empregados" onde o trabalho é ininterrupto e nas variadas formas de violência.

Esses trabalhadores têm em média 40 anos, baixa escolaridade e a maioria procede de regiões muito pobres, especialmente Maranhão, Alagoas, Minas Gerais e das periferias das cidades do Norte Fluminense.

É uma população submetida às precárias condições de produção e reprodução em que se sobressaem a péssima qualidade de água e alimentos oferecidos, alojamentos inadequados, ambientes sem higienização, aprisionamento por dívidas, descontos abusivos nos salários, esforço físico intenso, exposição à radiação solar, jornadas exaustivas, metas e pagamento por produção, falta de informação sobre o preço da tonelada de cana cortada e baixa cobertura de direitos trabalhistas e previdenciários, como expressam algumas falas de entrevistados: estavam dormindo em lugares ao onde passavam ratos, inseto e tudo (Entrevistado 1), o cara é forçado a cortar um caminhão de cana por dia, um caminhão de cana tem 18 até 22 toneladas e você imagine só uma pessoa fazer isso, você tem que pagar o que você come ... só que o que você trabalha já não dá mais nem para se sustentar.

Além dessas condições, existe uma problemática psicossocial, pois os entrevistados relevaram o baixo reconhecimento social do corte da cana, visto sempre como vergonhoso, pois ser cortador de cana é ser sujo, o tempo todo é a vergonha de entrar no ônibus sujo. [...] Então eles têm muita vergonha. Sacaneiam o outro o tempo todo. [...] Ih, aquele ali corta cana, durante o dia, corta cana (Entrevistado 2). Tudo isso gera uma ideologia de vergonha, que é um poderosíssimo mecanismo de submissão, a ponto desse trabalho poder ser classificado como um dirty work (trabalho sujo), uma atividade desvalorizada socialmente.

O medo é também muito presente entre os trabalhadores, pois estão expostos a pressões de encarregados, violências e coações físicas, verbais e simbólicas: Tem lugar aqui em Campos que ainda tem neguinho que bate nos outros... tem histórias de arrepiar; Quando chega [a pastoral da terra] encontra o pessoal com muito medo; tem gente que não toca no assunto porque ainda pode ser reprimido. Em algumas regiões do Brasil, o medo é tão intenso que muitos trabalhadores têm diarreia, febre e vômitos durante as ações do MTE e da Polícia Federal ${ }^{21}$.
A culpa é outro elemento frequente a ponto de os trabalhadores atribuírem a si as causalidades dos acidentes e sofrimentos. Se o erro tem, o erro é seu. Não é da empresa. Né... eu to clandestino e clandestino tem uma conotação de estar escondido, de estar errado. Tem um erro aí, mas não é do empregador, é do empregado (Entrevistado 3). Essa culpabilização individual proporciona, segundo Bourdieu ${ }^{28}$, a acusação da vítima, "única responsável por sua infelicidade” em detrimento das causalidades sociais dos sofrimentos.

Foram relatados ainda fadiga, mal-estar, desânimo, nervosismos, sentimentos de rancor e insatisfação que prejudica a confiança até para conquistas amorosas. Entre os migrantes a sensação de fracasso e revolta eclode quando percebem que foram enganados.

Essas condições classificadas como TE representam condicionantes geradores de processos nocivos à saúde dessa população e desgastes concretos no plano orgânico e psíquico além serem fonte de mal-estar e deterioração da autoimagem, autoestima e dignidade dos trabalhadores ${ }^{30}$.

A despeito das estruturas e recursos existentes na região para intervir no quadro sociossanitário desses trabalhadores, a exemplo dos Centros de Referência em Saúde do Trabalhador (Cerest), Centros de Atenção Psicossocial (Caps) e Assistência Social, não foram identificadas ações planejadas, articuladas e direcionadas à atenção integral às necessidades desses trabalhadores.

As ações institucionais mais frequentes são feitas pelo MTE, MPT e Polícia Federal com caráter repressivo e punitivo, mas as condições experimentadas pelos trabalhadores demandam estratégias de enfoques diferentes. O olhar cuidadoso para as necessidades específicas dos trabalhadores e as múltiplas dimensões do problema requerem a ampliação das práticas de "libertação", indenizações, pagamento de salários e seguros e garantia de retorno à terra natal, no caso de migrantes.

Além das punições e embargos aos empregadores, é fundamental desenvolver programas de assistência integral aos trabalhadores tanto nos territórios de origem quanto na região de trabalho e traçar ações de longo, médio e curto prazo que modifiquem as condições de empregabilidade desses sujeitos.

Cerest e Caps podem articular ações específicas frente aos sofrimentos dos trabalhadores, principalmente porque se trata de população pobre que nem sempre recebe olhar atento à sua dimensão psicossocial, frequentemente colocada em segundo plano. 
Apesar da ausência dessas ações específicas, a pesquisa no NF demonstrou o relevante e estratégico papel da saúde pública na identificação de casos de TE. Em Campos, uma investigação iniciada a partir da internação de trabalhadores em uma unidade de urgência e emergência deflagrou a presença de TE em fazendas.

Um grupo de doze homens fora internado com dores intestinais, ânsias de vômito e dores de cabeça. Eram trabalhadores de uma usina de cana-de-açúcar. Estavam infectados e profissionais buscaram compreender a relação entre o mal-es$\operatorname{tar}$ e as condições de trabalho. As investigações culminaram em articulações com o Ministério Público e a Polícia e chegou-se à inspeção das condições de habitação, higiene e trabalho constatando-se a má qualidade da água e dos barracões oferecidos, além dos baixos salários e a falta de equipamentos de segurança coletivos e individuais. A busca de compreensão da relação entre a condição de saúde e de trabalho foi o gatilho para iniciar a ação intersetorial com foco na saúde dos trabalhadores.

O reconhecimento público do problema do TE na região vem possibilitando maior atenção a esses "eventos sentinelas" específicos. Assim, entradas de trabalhadores do corte de cana acidentados ou enrijecidos por câimbras em postos de saúde e hospitais podem ser entendidas como sinalizadores da presença de situações aviltantes. Isso demonstra que uma unidade de saúde foi estratégica para identificar o TE e assim os serviços do SUS podem contribuir para descobrir casos e deslanchar ações intersetoriais de vigilância efetivas e resolutivas.

Unidades da atenção básica, postos de urgência e emergência são portas abertas e, portanto, pontos de alerta ao TE, mas outras unidades e demais níveis de atenção têm potencial para colaborar também na atenção integral aos trabalhadores conforme as particularidades de cada região e são capazes de gerar ações de fiscalização de processos de trabalho articuladas pela vigilância em saúde do trabalhador (Visat).

Tudo isso depende do reconhecimento e legitimaçã̃o ${ }^{10,11}$ dessas condições enquanto problemas também do campo da saúde pública. Nesse sentido, um ponto importante revelado na investigação foi exatamente o papel exercido pela sociedade civil no reconhecimento público do TE e na mobilização de intervenções. Entidades da sociedade têm lutas contínuas contra o TE, e, na região, as ações levaram à criação do CPETE que faz uma vigilância constante dessas situações. A gente fica de olho nesses alojamentos [...] chegaram muitos ônibus de Alagoas e do Vale do Jequitinhonha, aí já tinham alagoanos, tinha trabalhador doente, tinha trabalhador com suspeita de tuberculose, tinha trabalhador que estava com problema de coluna sério, e ficava no alojamento e sem receber, sem nada.

Conforme Berger, Luckmann ${ }^{10}$ e Lenoir ${ }^{11}$ pode-se dizer que esses atores sociais locais despertam a sociedade e as instituições para reconhecer e agir sobre o problema social. Aliás, para a PNSTT $^{9}$, esse olhar e vigiar ativo da sociedade civil organizada é elementar para a Visat. Esse caso demonstra a importância das investigações e informações produzidas pelos movimentos sociais para ações participativas em Visat. O envolvimento de profissionais de vigilância epidemiológica, ambiental, sanitária com os movimentos sociais é fundamental para ampliar a vigilância do TE.

Nas ações da sociedade civil regional destaca-se a estratégia de intervir na cadeia produtiva, pois as práticas do CPETE não se resumem a denúncias. $\mathrm{O}$ comitê acessou um agente importante na cadeia produtiva para convencê-lo a não comprar álcool de uma usina envolvida em TE e essas ações tiveram êxito em alguns momentos. Essa experiência mostra uma alternativa para intervir no TE, a partir da cadeia produtiva que possibilita uma atuação extremamente relevante em saúde. Mapear cadeias de produção pode revelar territórios da vulnerabilidade ao TE e gerar planejamentos estratégicos de ações de vigilância.

É importante destacar ainda o papel dos próprios trabalhadores para modificar esse quadro. No NF, eles ocuparam um lugar histórico de reinvindicação e os órgãos da sociedade civil começaram a se articular em função de suas demandas. A criação do CPETE, inclusive, foi uma consequência da manifestação de migrantes na região. Apesar das imagens muitas vezes veiculadas do trabalhador escravizado como uma vítima passiva da exploração, em Campos, o que se observou foi sua indignação e protagonismo na transformação da realidade social.

\section{Considerações finais}

$\mathrm{O}$ artigo demonstrou que o trabalho escravo contemporâneo se configura como problema de saúde pública não apenas devido aos efeitos físicos e psíquicos da humilhação, violência e superexploração dos trabalhadores. A existência do TE evidencia contradições e complexidades culturais, sociais, políticas e econômicas do Brasil e 
demonstra claramente iniquidades sociais e de saúde. Ele revela um quadro sócio-sanitário-ocupacional problemático demais para ser categoria excluída do campo da saúde.

Certamente, esse fenômeno vem sendo reconhecido pelo campo das relações saúde, trabalho e ambiente, entretanto faltam estratégias direcionadas para sua efetiva incorporação nas práticas institucionais de modo a viabilizar sua inserção na agenda do SUS. Mas os dados empíricos aqui evidenciados contribuíram no sentido de dar visibilidade ao papel e à potencialidade do setor saúde para identificar e intervir no TE não apenas na região estudada, mas para o cenário nacional.

Seria pertinente então incluir o TE no âmbito da pesquisa em saúde pública para proporcionar compreensões mais acuradas sobre suas manifestações e seus determinantes. Seria igualmente pertinente e relevante desenvolver estratégias institucionais, superando paradigmas biomédicos que dificultam a incorporação dessas condições no âmbito da ação em saúde. Isso depende de atores interessados em trazer à tona essa problemática e exigir soluções político-institucionais.
Considerando que as dimensões da causalidade e os efeitos do TE demandam ações robustas do Estado e da Sociedade, compete à saúde pública integrar-se mais aos atores já envolvidos no combate, para construir estratégias de atenção integral a essa população, conforme a capacidade instalada no SUS, e de vigilância do trabalho escravo, em caráter intersetorial e participativo.

É importante dizer que muitos Cerest têm assento em conselhos, comissões e fóruns de combate ao TE e têm condições de elaborar conjuntamente tais estratégias. Atualmente existem 210 Cerest em funcionamento e muitos deles estão localizados em regiões de alta incidência de TE, como Mato Grosso, Pará, Maranhão e Rio de Janeiro. Cabe a eles articularem-se com movimentos sociais e atores governamentais, compondo um coletivo de ação em cada espaço e território, para desenvolver projetos e programas de identificação, prevenção, controle, vigilância e atenção integral à saúde desses trabalhadores submetidos a condições aviltantes. Afinal, não existem tratamentos, vacinas, medicamentos ou soluções milagrosas para tratar essas condições sociais crônicas. 


\section{Referências}

1. Fapesp. Brasil líder mundial em conhecimento e tecnologia de cana e etanol. São Paulo: Fapesp; 2007.

2. Phillips N, Sakamoto L. Global Production Networks, Chronic Poverty and 'Slave Labour' in Brazil. Stud Comp Int Dev 2012; 47:1-29.

3. Galeano E. As veias abertas da América Latina. Buenos Aires: Siglo Veintiuno Editores; 2010.

4. The Global Slavery index. What is modern slavery? [acessado em 2015 jan 23]. Disponível em: http://migre.me/oyE0E

5. Reis T. Libertações por trabalho escravo na área urbana superam as do campo. G1. [acessado $2014 \mathrm{fev} \mathrm{17].} \mathrm{Dis-}$ ponível em: http://migre.me/ou9Dj

6. Brasil. Ministério do Trabalho (MT). Quadro geral das operações de fiscalização para erradicação do trabalho escravo - SIT/SRTE 1995 a 2012. [acessado em 2013 jun 29]. Disponível em: http://migre.me/ou9t3

7. Free the slaves. Hidden slaves. Forced labor in the United States. Berkeley: Human Rights Center University of California; 2004.

8. Moura FAV, Leão LHC. Saúde pública e erradicação do trabalho escravo em Mato Grosso. Est Cont Subjetividade 2014; 4(2):213-226.

9. Brasil. Portaria no 1.823 , de 23 de agosto de 2012. Institui a Política Nacional de Saúde do Trabalhador e da Trabalhadora. Diário Oficial da União 2012; 24 ago.

10. Berger P, Luckman T. A construção social da realidade. Petrópolis: Vozes; 2008.

11. Lenoir R. Objeto sociológico e problema social. In: Champagne P, Lenoir R, Merllié D, Pinto L. organizadores. Iniciação à Prática sociológica. Petrópolis: Vozes; 2006. p. 59-106.

12. Costa JSD, Victora CG. O que é "um problema de saúde pública”?. Rev. bras. epidemiol 2006; 9(1):144-146.

13. Brown P, Zavestoski S. Social movements in health: an introduction. Sociol. Health Ill 2004; 26(6):679-694.

14. Martins JS. A escravidão nos dias de hoje e as ciladas da interpretação. In: Comissão Pastoral da Terra. Trabalho Escravo no Brasil Contemporâneo. São Paulo: Ed. Loyola; 1999. p. 127-164.

15. Hardt M, Negri A. Império. Rio de Janeiro/São Paulo: Ed. Record; 2005.

16. Hegel GWF. Fenomenologia do espírito. Petrópolis: Vozes; 1992.

17. Marx K. Trabalho Assalariado e Capital. São Paulo: Global Editora; 1987.

18. Hayek FAV. O caminho da servidão. São Paulo: Instituto Ludwig von Mises Brasil; 2010.
19. La Boétie E. O discurso da servidão voluntária. São Paulo: Martin Claret; 2009.

20. Bales K. Disaposable people: new slavery in the global economy. Berkeley, Los Angeles: University of California Press; 1999.

21. Figueira RR, Prado AA. Trabalho Escravo por Dívida e Condições Degradantes na Área de Saúde. Saúde e Direitos Humanos 2010; 6:57-70.

22. Rosen G. A evolução da medicina social. In: Nunes ED, organizador. Medicina Social: Aspectos históricos e teóricos. São Paulo: Global; 1983. p. 25-82.

23. Organização Internacional do Trabalho (OIT). Perfil dos principais atores envolvidos no trabalho escravo rural no Brasil. Brasília: OIT; 2011.

24. Brasil. Ministério da Saúde (MS). Rede nacional de atenção integral à saúde do trabalhador: Manual de gestão e gerenciamento. São Paulo: Hemeroteca Sindical Brasileira; 2006.

25. Brasil. Ministério da Saúde (MS). Doenças relacionadas ao trabalho: manual de procedimentos para os serviços de saúde. Brasília: Ed. Ministério da Saúde; 2001.

26. Brasil. Ministério da Saúde (MS). Conselho Nacional de Saúde. Relatório Final da $13^{a}$ Conferência Nacional de Saúde. Brasília: Ed. Ministério da Saúde; 2008.

27. Laboratório de informação em saúde/Icict/Fiocruz. [homepage da internet]. Mapa de conflitos envolvendo injustiça ambiental e saúde no Brasil. [acessado 2014 jun 17]. Disponível em: http://www.conflitoambiental. icict.fiocruz.br/

28. Bourdieu P. Contrafogos. Táticas para enfrentar a invasão neoliberal. Rio de Janeiro: Zahar; 1998.

29. Sennett R. A cultura do novo capitalismo. Rio de Janeiro: Record; 2006.

30. Seligmann-Silva E. Trabalho e desgaste mental. O direito de ser dono de si mesmo. São Paulo: Cortez; 2011.
Artigo apresentado em 02/03/2015

Aprovado em 14/09/2015

Versão final apresentada em 16/09/2015 